\title{
Photo-oxidation of EPDM/layered double hydroxides composites: Influence of layered hydroxides and stabilizers
}

\author{
B. Kumar, S. Rana, R. P. Singh* \\ Division of Polymer Science and Engineering National Chemical Laboratory, Dr. Homi Bhabha Road, Pune-411008, \\ India
}

Received 4 May 2007; accepted in revised form 1 October 2007

\begin{abstract}
The photo-oxidation of ethylene propylene diene monomer (EPDM)/ layered double hydroxide (LDH) composites as well as EPDM/LDH with stabilizers is studied under accelerated UV irradiation $(\lambda \geq 290 \mathrm{~nm})$ at $60^{\circ} \mathrm{C}$ for different time intervals. The development of functional groups during oxidation was monitored by FT-IR spectroscopy. The photodegradation of the pristine polymer and composites take place and the increase in hydroxyl and carbonyl groups with irradiation times, was estimated. EPDM filled LDH showed higher degradation rate than pristine EPDM, while in acidic medium EPDM/LDH showed almost equal degradation as in isolated conditions. These results show the advantages of LDHs as a filler as well as an acid killer. The effect of stabilizers is very less because of their concentration in comparison of LDH.
\end{abstract}

Keywords: polymer composites, layered double hydroxides, EPDM, photo-oxidation

\section{Introduction}

Composites of organic and inorganic compounds represent an important class of engineering materials $[1,2]$. Amongst the inorganic materials, smectite clays have received considerable attention because their structure exhibits the required stiffness, strength and dimensional stability. In recent years, it has been found that layered double hydroxides (LDHs), also known as hydrotalcite-like compounds (HTlcs), have attracted great attention [3-9], because of their layered structure and high anion-exchange capacity, which enables various technical applications $[10,11]$. The structure consists of positively charged brucite (magnesium hydroxide)-like layers with interlayer space containing charge compensating anions and water molecules. The metal cations occupy the centers of octahedra whose vertexes contain hydroxide ions. The octahedra are connected by edge sharing to

*Corresponding author, e-mail: rp.singh@ncl.res.in

(C) BME-PT and GTE form an infinite sheet $[12,13]$. The general formula of the compounds is $\left[\mathrm{M}^{2+}{ }_{1-x} \mathrm{M}^{3+}{ }_{x}(\mathrm{OH})_{2}\right] \mathrm{A}^{n-}{ }_{x / n} m \mathrm{H}_{2} \mathrm{O}$, where $\mathrm{M}^{2+}$ and $\mathrm{M}^{3+}$ are divalent $\left(\mathrm{Mg}^{2+}, \mathrm{Zn}^{2+}, \mathrm{Ni}^{2+}\right.$, etc.) and trivalent cations $\left(\mathrm{Al}^{3+}, \mathrm{Cr}^{3+}\right.$, etc. $), \mathrm{A}^{\mathrm{n}-}$ is a non-framework charge compensating anion (such as $\mathrm{CO}_{3}{ }^{2-}, \mathrm{Cl}^{-}, \mathrm{SO}_{4}{ }^{2-}$ ), and $x$ is normally between 0.17 and 0.33 . The structure is shown in (Figure 1). Layered double hydroxides and their derivatives are inorganic materials with a positive layer charge in which the interlayer anions can be replaced by ion-exchange processes. Owing to its high anion-

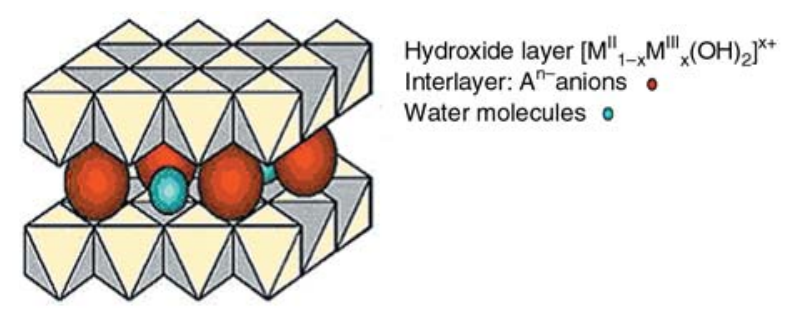

Figure 1. Structure of layered double hydroxide 
exchange capacity, LDHs have found many potential applications, including those in pharmaceuticals, catalyst supports, inorganic fillers and acid killers [14] to prevent the degradation of polymeric materials by effectively scavenging any acid generated during processing as well as during application.

Ethylene propylene diene monomer (EPDM) rubber is widely used due to its good mechanical properties, very low unsaturation and associated resistance to ageing and ozone deterioration [15]. This is due to its saturated hydrocarbon backbone with the presence of double bonds in side chains. It has been extensively used in making automotive tire, side walls, cover strips, wires, cables, hoses, belting, roofing barriers and sporting goods. Due to its outdoor applications, the study of its durability in acidic environment is extremely important for industry as well as academic point of view. Only a few reports have focused on the degradation of EPDM rubbers in specific aggressive acidic environments [16-19].

To the best of our knowledge, the effect of LDHs on the acidic degradation of EPDM/LDHs composites has not yet been reported. In order to derive a more detailed understanding of the various factors influencing the effect of different stabilizers, the filler concentration (composition) was kept constant. This paper deals the degradation of EPDM/ LDH composites in acidic environment in presence of polychromatic irradiation $(\lambda \geq 290 \mathrm{~nm})$. The effect of commercial stabilizers in composites has also been studied.

\section{Experimental}

\subsection{Materials}

The elastomer used was commercial Ethylene Propylene Diene Monomer (EPDM) (ethylene: propylene: diene (5-ethylidene-2-norbornene) 55:41:4.) supplied by M/s. Sediver, France. EPDM rubber was purified by dissolving in toluene solution and precipitating from acetone to remove the additives. The commercial grade thiourea (ethylenethiourea, NPV/C), sulfur, zinc oxide, stearic acid were purchased from S.D. Fine Chemicals Ltd, India. Layered double hydroxide (LDH) was synthesized in our laboratory. The conventional stabilizers (Irganox 1076, Irganox 1010, Tinuvin-P) were obtained from M/s Ciba Geigy India Pvt. Ltd., Mumbai, India.

\subsection{Synthesis of layered double hydroxide (acid killer)}

For the synthesis of $\mathrm{LDH}(\mathrm{a} \mathrm{Mg} / \mathrm{Al}$ double-layered hydroxide) of formula:

$\left[\mathrm{Mg}_{3} \mathrm{Al}(\mathrm{OH})_{8}\right]^{+}\left[0.5 \mathrm{CO}_{3}^{-} \cdot m \mathrm{H}_{2} \mathrm{O}\right]^{-}$, an aqueous solution $(250 \mathrm{ml})$ containing $\mathrm{Mg}\left(\mathrm{NO}_{3}\right)_{2} \cdot 6 \mathrm{H}_{2} \mathrm{O}$ and $\mathrm{Al}\left(\mathrm{NO}_{3}\right)_{2} \cdot 9 \mathrm{H}_{2} \mathrm{O}$ with a ratio of $\mathrm{Mg} / \mathrm{Al}(3: 1)$ were slowly added to a second solution $(250 \mathrm{ml})$ of $\mathrm{NaOH}(0.675 \mathrm{~mol})$ and $\mathrm{NaNO}_{3}(0.2 \mathrm{~mol})$ under vigorous stirring at $65^{\circ} \mathrm{C}$. The addition took nearly $2 \mathrm{hrs}$. The precipitate formed was filtered and washed thoroughly with $500 \mathrm{ml}$ de-ionised water (at least until the $\mathrm{pH}$ of the filtrate was 7) and freeze dried and then aged for $20 \mathrm{hrs}$ at $20^{\circ} \mathrm{C}$ in their mother liquor and then filtered, washed and dried. The samples were hydrothermally treated using microwave heating ( $8 \mathrm{hrs}$ with a step-wise increase in temperature from 120 up to $180^{\circ} \mathrm{C}$ and a corresponding pressure of 2-10 bar). The crystalline phases were characterized by X-ray diffraction [20].

\subsection{Preparation of EPDM-layered double hydroxides composites}

$\mathrm{LDH}$ was mixed with EPDM at $180^{\circ} \mathrm{C}$ with $70 \mathrm{rpm}$ for 5 minutes by using a twin-screw extruder (DSM, MICRO-5). The screw length was $1365 \mathrm{~mm}$ and $L / D$ was 45.5 , the LDH concentration was kept $5 \mathrm{wt} \%$, vulcanizing agents were added as shown in Table 1. The mixing of EPDM/LDH hybrid and vulcanizing agents (Zinc oxide $-5 \%$, Stearic acid $1 \%$, Sulfur $-1.8 \%$ and Thiourea $-1.5 \%$ ) were mixed at $90^{\circ} \mathrm{C}$ for $3-5$ minutes. EPDM composites were also filled with stabilizers (Irganox 1076, Irganox 1010 and Tin-P concentration were $0.5 \mathrm{wt} \%)$. For comparative study, EPDM samples

Table 1. Composition of the composites

\begin{tabular}{|c|c|c|c|l|}
\hline S.No & $\begin{array}{c}\text { LDHs } \\
{[\mathbf{w t} \%]}\end{array}$ & $\begin{array}{c}\text { Vulcanization } \\
\text { agents }^{*}[\mathbf{w t} \%]\end{array}$ & $\begin{array}{c}\text { Stabilizers 0.5 } \\
{[\mathbf{w t} \%]}\end{array}$ & $\begin{array}{c}\text { Sample } \\
\text { code }\end{array}$ \\
\hline 1 & - & 9.3 & - & EP-Neat \\
\hline 2 & 5 & 9.3 & - & EP-H \\
\hline 3 & 5 & 9.3 & Irganox 1076 & EP-I 76 \\
\hline 4 & 5 & 9.3 & Irganox 1010 & EP-I 10 \\
\hline 5 & 5 & 9.3 & Tinuvin-P & EP-Tin P \\
\hline
\end{tabular}

*Zinc oxide $-5 \%$, Stearic acid $-1 \%$, Sulfur $-1.8 \%$ and Thiourea $-1.5 \%$ 
were prepared without LDH (only vulcanizers) under same experimental conditions [21]. All composites were molded into films (thickness $\approx$ $100 \mu \mathrm{m})$ at $160^{\circ} \mathrm{C}$ by using the hydraulic press for 10 minutes.

\subsection{Photoirradiation}

The photo-irradiation experiments were carried out in accelerated weathering chamber SEPAP 12/24 (M/s Material Physico Chimique, Neuilly/Marne, France) at $60^{\circ} \mathrm{C}$. The chamber consists of $(4.400 \mathrm{~W})$ medium pressure mercury vapor lamps supplying radiation $(\lambda \geq 290 \mathrm{~nm})$. The instrument is described elsewhere [22]. Nitric acid treated samples were also irradiated in chamber under same conditions. For acidic treatment, the samples were kept in vapour phase in a desicator, containing 5\% nitric acid concentration for $3 \mathrm{hrs}$ after every $25 \mathrm{hrs}$ degradation intervals.

\subsection{Measurement of photostabilizing efficiency}

The photostabilizing efficiency of LDH on EPDM was monitored by the measurement of the carbonyl and hydroxyl group changes by FT-IR spectroscopy. The IR absorption spectral changes of the film upon irradiation with $300 \mathrm{~nm}$ UV light were observed for different time intervals. The data obtained were compared with pristine EPDM and EPDM/LDH with and without conventional stabilizers (Irganox 1076, Irganox 1010, Tin-P) under similar accelerated conditions.

\subsection{Transmission electron microscopy (TEM)}

Transmission electron microscopy (TEM) observation of EPDM/LDH composites was performed with a Philips CM300 FEG TEM instrument operated under an acceleration voltage of $300 \mathrm{kV}$. Thin sections (thickness $\approx 200 \mathrm{~nm}$ ) for TEM observations were cut from the as-prepared composites under cryogenic conditions using a Leica ultramicrotome with a diamond knife (Figure 2).

\subsection{Scanning electron microscopy}

Surface changes of the irradiated samples were examined by SEM. The stained samples were dried under vacuum for $24 \mathrm{~h}$ at $50^{\circ} \mathrm{C}$ and the gold-coated

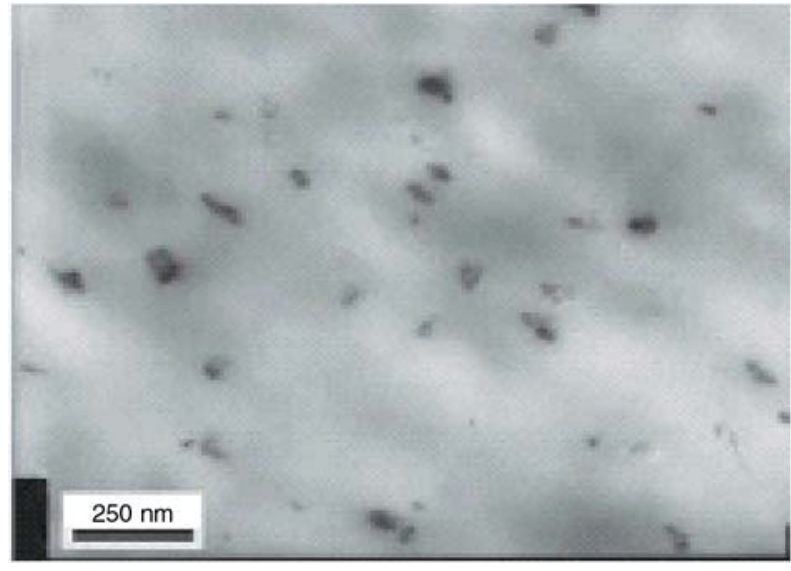

Figure 2. TEM image showing LDHs dispersion

samples were examined under electron microscope (Leica Cambridge Stereoscan 440 Model).

\section{Results and discussion}

\subsection{Characterization}

The LDH was characterized by XRD according to literature [20]. The XRD data between 2 and $70^{\circ}$, were recorded at $0.5^{\circ} / \mathrm{min}$, using $\mathrm{CuK}_{\alpha}$ radiation at a generator voltage of $40 \mathrm{kV}$.

The $\left[\mathrm{Mg}_{3} \mathrm{Al}(\mathrm{OH})_{8}\right]^{+}\left[0.5 \mathrm{CO}_{3}^{-} \cdot m \mathrm{H}_{2} \mathrm{O}\right]^{-}$shows a basal 001 reflection at $d=7.9 \AA$. This reflection corresponds to the interlayer distances.

\subsection{Degradation products}

FT-IR spectroscopy was successfully used to study the degradation pattern and products in polymers $[23,24]$. The rate of photo-oxidation was followed by monitoring the development in carbonyl and hydroxyl region by FT-IR spectra for different time intervals from 0 to $100 \mathrm{hrs}$. The increase of absorbance in the hydroxyl and carbonyl region was studied as a function of irradiation time. The absorbance of the ethylidene units at $808 \mathrm{~cm}^{-1}$ dramatically decreases and new bands appeared at 910 and $970 \mathrm{~cm}^{-1}$, which can be assigned, respectively, to the vinyl-type unsaturations coming from Norrish II type reactions (Figure 3) and to $\mathrm{CH}$ wag of the other double bonds derived from hydrogen abstraction reactions on allylic positions during the photooxidation as already reported in the case of EPDM [25-26] and the photoproducts of composites were same as in the pristine EPDM [22]. Figures 4 and 5 show the IR region for the evolution of carbonyl and hydroxyl regions, respectively, of the composites [EP-H] upon UV irradiation. The 


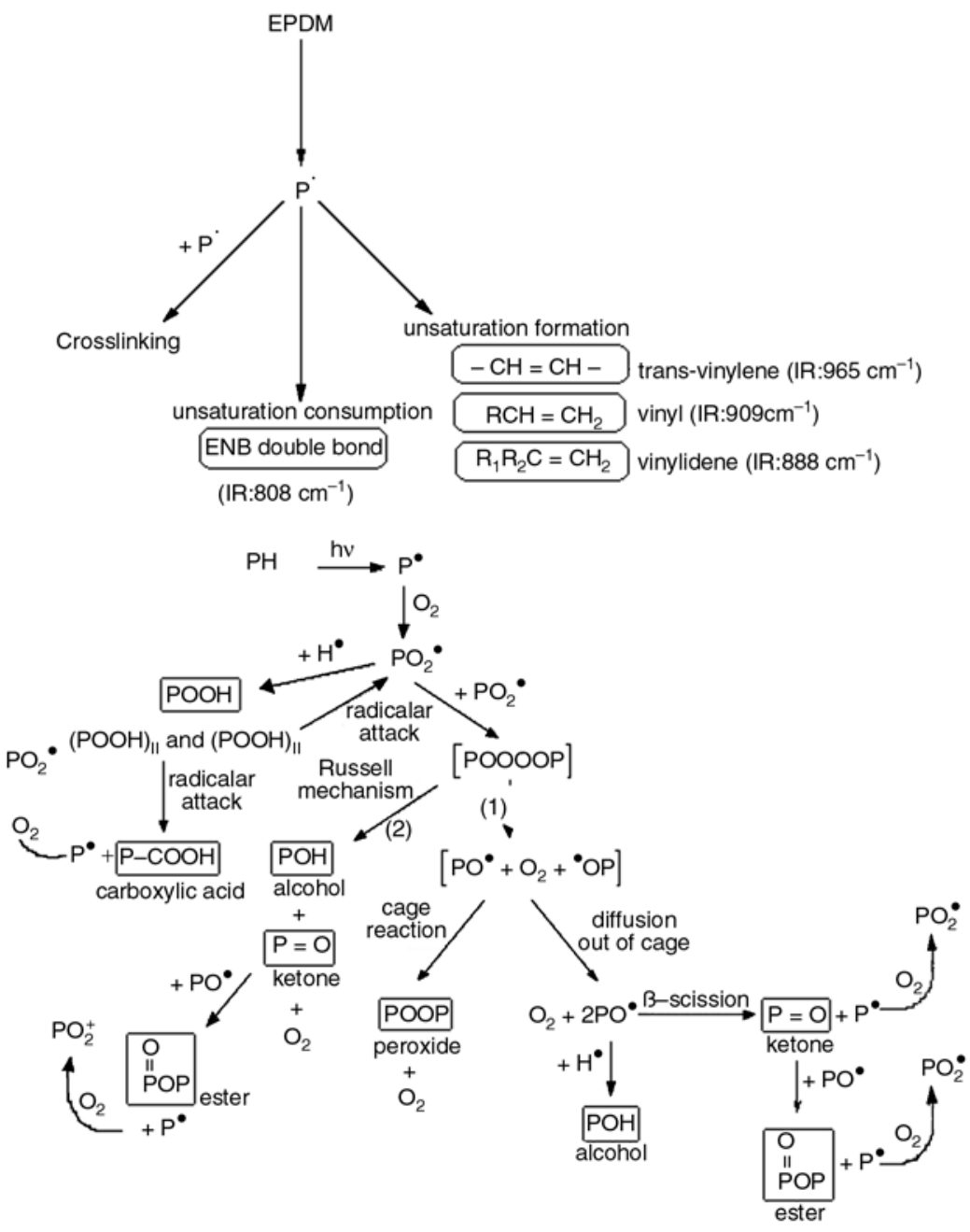

Figure 3. Simplified mechanism of EPDM degradation

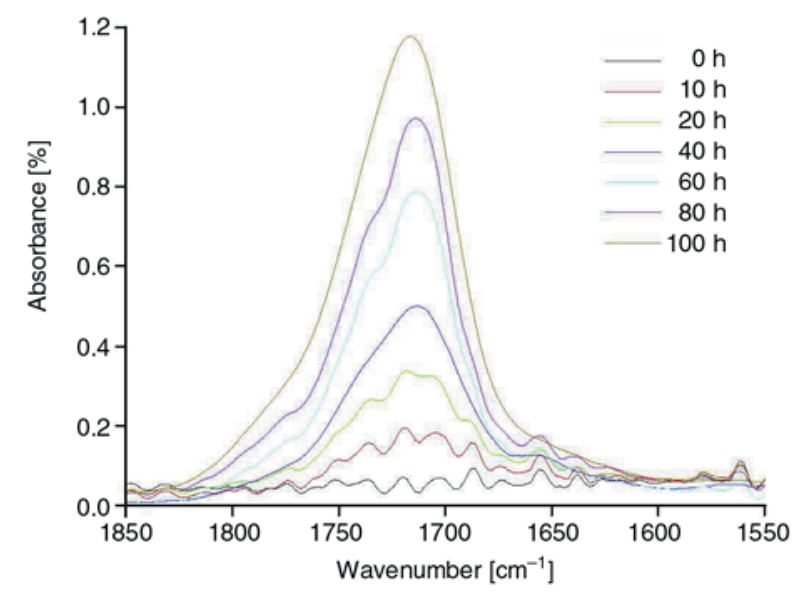

Figure 4. Evaluation of carbonyl region of EPDM/LDHs composites during photo-oxidation

increase in these regions may be attributed to the degradation of polymer matrix, which may lead to chain scission. The spectra showed that the induction period is reduced in the presence of LDH. In presence of the stabilizers also, the induction period is less than that of pristine EPDM and it may be due

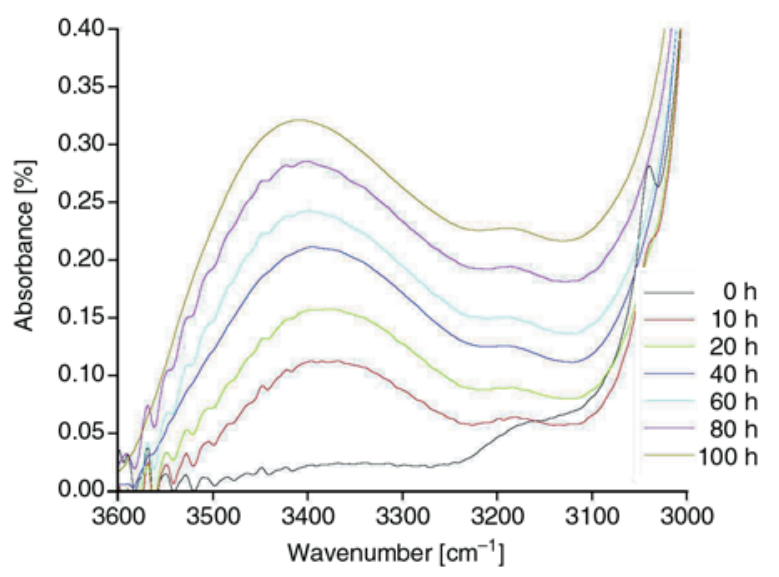

Figure 5. Evaluation of hydroxyl region of EPDM/LDHs composites during photo-oxidation

to interaction between the phenol groups of stabilizers and LDH. The vibrations at 1780, 1735, 1721 and $1710 \mathrm{~cm}^{-1}$ have been assigned for lactone, ester, ketone and acid groups, respectively. In the hydroxyl region, a large absorption band was observed with a maximum at $3400 \mathrm{~cm}^{-1}$, which is 
due to oxidized products such as hydroperoxides and alcohols, whereas the rate of formation of these products was higher in composites than neat film. Both, the carbonyl and hydroxyl regions were increased similarly and were faster than in the pristine EPDM where no additional peak could be observed in the present system (Figures 6 and 7). This phenomenon confirms that the presence of filler influences the degradation of EPDM but degradation products remain the same. Transition Metal elements viz., $\mathrm{Mn}(\mathrm{II}), \mathrm{Fe}(\mathrm{III}), \mathrm{Ru}(\mathrm{II}), \mathrm{Co}(\mathrm{II})$, etc., play a key role to enhance the rate of hydroperoxide decomposition [27]. The reason to increase the rate of degradation may be due to the presence of metal ions; which may catalyze the decomposition of hydroperoxide to alkoxy or peroxy radicals by the following mechanism and may therefore, accelerate the photo-oxidation of polymers as shown in Figure 8.

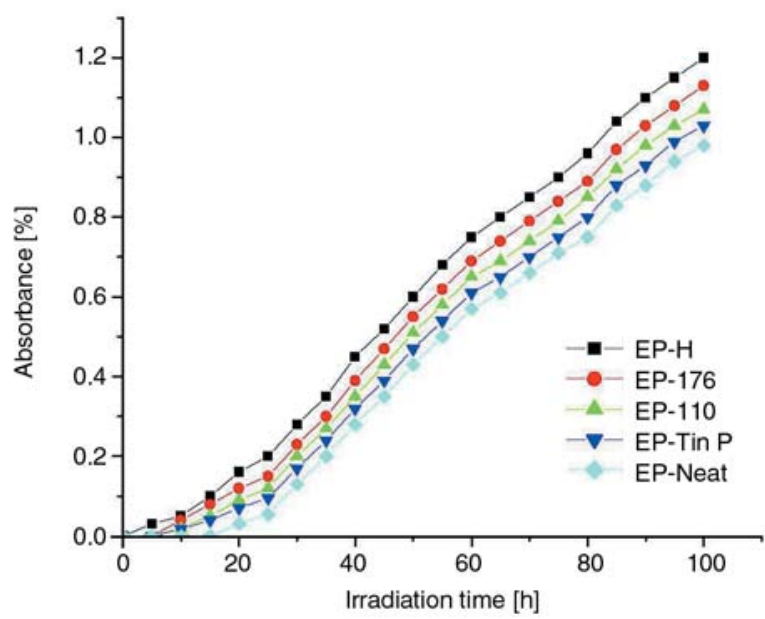

Figure 6. Evaluation of carbonyl region as a function of irradiation time duringphoto-oxidation

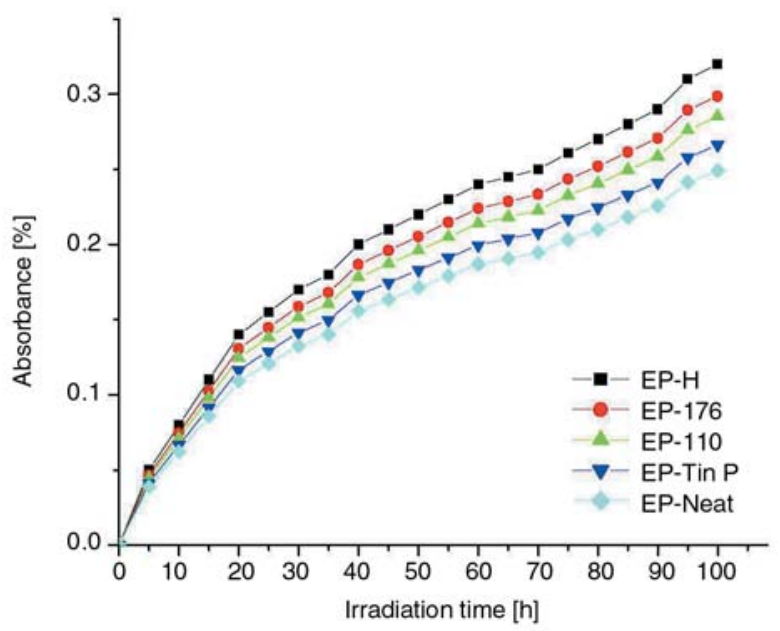

Figure 7. Evaluation of hydroxyl region as a function of irradiation time duringphoto-oxidation

$$
\begin{aligned}
& \mathrm{R}+\mathrm{O}_{2} \rightarrow \mathrm{RO}_{2} \\
& \mathrm{RO}_{2}{ }^{\circ}+\mathrm{RH} \rightarrow \mathrm{ROOH}+\mathrm{R}^{\circ} \\
& \mathrm{ROOH}+\mathrm{M}^{\prime \prime} \rightarrow \mathrm{RO}+\mathrm{M}^{\prime \prime} \mathrm{OH} \\
& \mathrm{M}^{\mathrm{II}} \mathrm{OH}+\mathrm{ROOH} \rightarrow \mathrm{M}^{\prime \prime \prime} \mathrm{OOR}+\mathrm{H}_{2} \mathrm{O} \\
& \mathrm{M}^{\prime \prime \prime} \mathrm{OOR} \rightarrow \mathrm{M}^{\prime \prime}+\mathrm{ROO} \\
& \mathrm{M}^{\prime \prime} \mathrm{OOR} \rightarrow \mathrm{MO}^{*}+\mathrm{RO}^{\circ} \\
& \mathrm{RO}^{\circ}+\mathrm{RH}^{\prime} \rightarrow \mathrm{ROH}+\mathrm{R}^{\prime}
\end{aligned}
$$

Figure 8. Mechanism of metal ions as initiator and catalysis to enhance photo degradation

The photo-degradation of the same compositions was studied in acidic conditions and was observed that EPDM/LDH composites showed interesting results (Figures 9 and 10). There is not much difference in the degradation rate in acidic and natural environment because of LDHs's acid killer nature, which enhances the LDH importance as filler. The

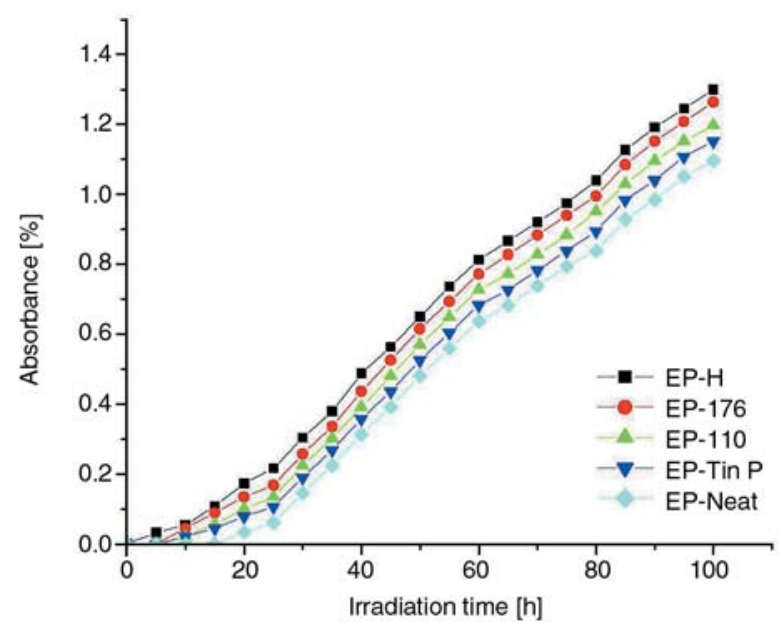

Figure 9. Evaluation of carbonyl region as a function of irradiation time during photo-oxidation in acidic environment

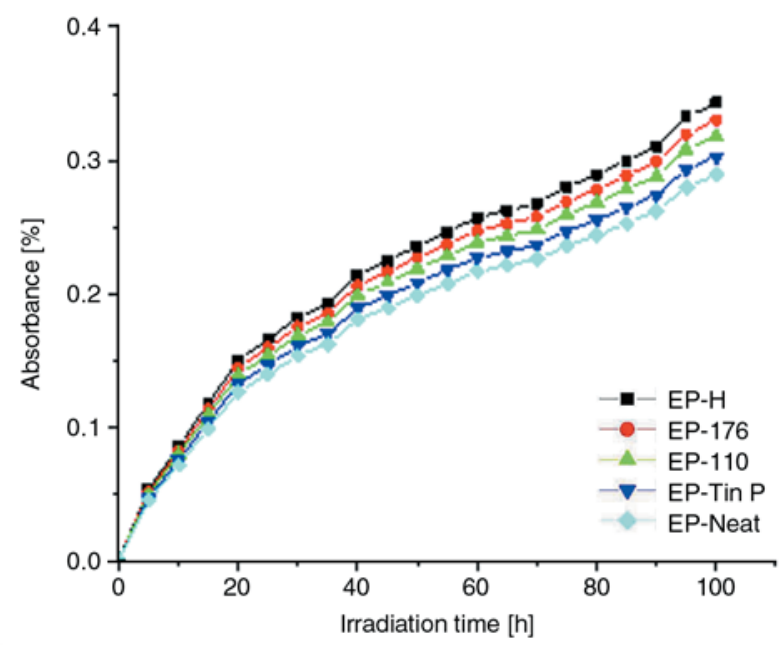

Figure 10. Evaluation of hydroxyl region as a function of irradiation timeduring photo-oxidation in acidic environment 


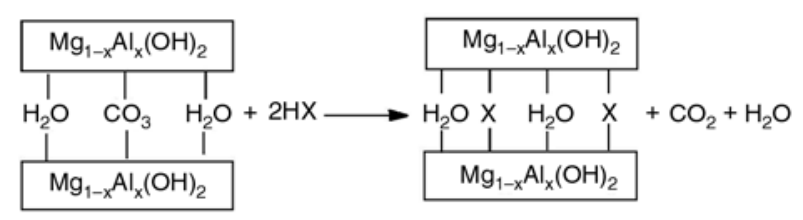

Figure 11. The acid killer mechanism of LDHs

mechanism of LDHs as an acid killer is described in Figure 11 where $\mathrm{X}=\mathrm{Cl}^{-}, \mathrm{NO}_{3}^{-}$, etc. The presence of stabilizers also does not show much effect on stabilization because of very low concentration in comparison to LDH, however, Tinuvin-P shows better stabilization in comparison to Irganox 1076 and Irganox 1010.

\subsection{Morphological aspects}

SEM is a reliable tool to monitor the surface chances during degradation of polymers and interesting micrographs are shown in Figures 12 and 13. The presence of highly eroded surface with small cavities in the samples, indicates the higher degradation after $100 \mathrm{hrs}$ irradiation. A scattering pattern of small patches was observed after UV irradiation, which must be due to the generation of more oxida-

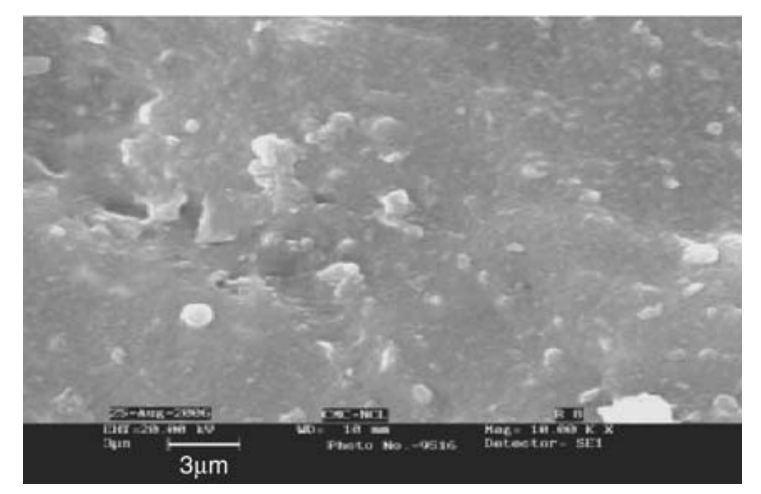

Figure 12. SEM study of EPDM/LDHs composites after 100 h Photo-degradation

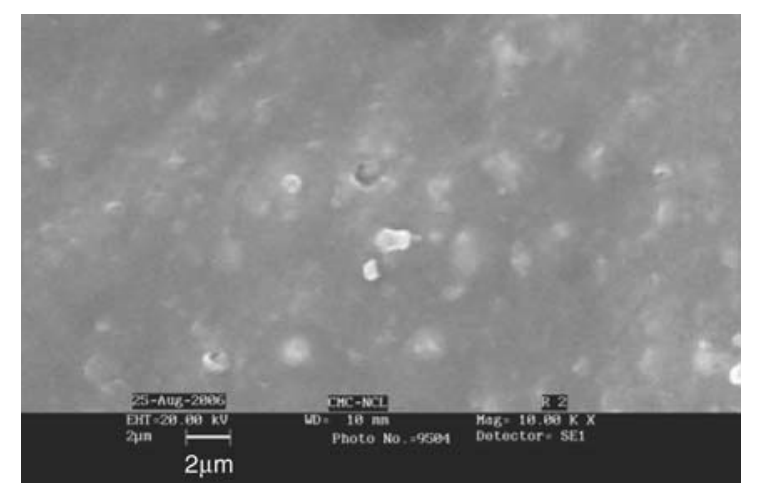

Figure 13. SEM study of pristine EPDM after $100 \mathrm{~h}$ Photo-degradation tion products in Figure 12 than in Figure 13, and this fact again supported the conclusion that presence of LDH enhances the degradation rate in acidic as well as isolated conditions.

\section{Conclusions}

The comparison of the kinetic curves showed the oxidation for the different samples which reveals an influence of LDH and the stabilisers on the formation of carbonylated photoproducts. It was observed that the photo-oxidative products were not changed after adding the filler, however, the rate of photo-oxidative degradation of EPDM/LDH composites is faster than that of pristine EPDM. LDHs showed good results in acidic conditions, which enhances its importance. The lower efficiency of the stabilizers could result because of high percentage LDH filler. It could be because of the adsorption of the additives onto the LDH, which partially inhibits their stabilizing activity.

\section{Acknowledgements}

The authors are grateful to Dr.S.Sivaram, Director, National Chemical Laboratory, Pune, India for his fruitful discussions and encouragement. Authors are also grateful to IFCPAR / CEFIPRA, New Delhi for financial support (Grant No. IFC/7104 Insulator).

\section{References}

[1] Rothon R.: Particulate-filled polymer composite. Wiley and Son, New York (1995).

[2] Pukánszky B.: Particulate filled polypropylene: structure and properties. in.: 'Polypropylene: structure, blends and composites' (ed.: Karger-Kocsis J.) Champman and Hall, London, Vol. 3, 1-70 (1995).

[3] Messersmith P. B., Stupp S. I.: High-temperature chemical and microstructural transformations of a nanocomposite organoceramic. Chemistry of Materials, 7, 454-460 (1995).

[4] Wilson O. C., Olorunyolemi T., Jaworski A., Borum L., Young D., Siriwat A.: Dickens E., Oriakhi C., Lerner M.: Surface and interfacial properties of polymer-intercalated layered double hydroxide nanocomposites. Applied Clay Science, 15, 265-279 (1999).

[5] Leroux F.: Aranda P., Besse J. P., Ruiz-Hitzky E.: Intercalation of poly(ethylene oxide) derivatives into layered double hydroxides. European Journal of Inorganic Chemistry, 2003, 1242-1251 (2003).

[6] Carlino S.: Chemistry between the sheets. Chemistry in Britain, 33, 59-62 (1997). 
[7] Messermith P. B., Stupp S. I.: Synthesis of nanocomposites: Organoceramics. Journal of Material Research, 7, 2599-2611 (1992).

[8] Oriakhi C. O., Farr I. V.: Lerner M.: Incorporation of poly(acrylic acid), poly(vinylsulfonate) and poly (styrenesulfonate) within layered double hydroxides. Journal of Materials Chemistry, 6, 103-107 (1996).

[9] Whilton N. T., Vickers P. J., Mann S.: Bioinorganic clays: synthesis and characterization of amino- and polyamino acid intercalated layered double hydroxides. Journal of Materials Chemistry, 7, 1623-1629 (1997).

[10] Cavani F., Trifiro F., Vaccari A.: Hydrotalcite-type anionic clays: Preparation, properties and applications. Catalysis Today, 11, 173-301 (1991).

[11] Choy J-H., Kwak S-K., Park J-S., Jeong Y-J., Portier J.: Intercalative nanohybrids of nucleoside monophosphates and DNA in layered metal hydroxide. Journal of the American Chemical Society, 121, 1399-1400 (1999).

[12] Costantino U., Marmottini F., Nocchetti M., Vivani R.: New synthetic routes to hydrotalcite-like compounds - Characterisation and properties of the obtained materials. European Journal of Inorganic Chemistry, 1998, 1439-1446 (1998).

[13] Yong Z., Mata V., Rodrigues A. E.: Adsorption of carbon dioxide at high temperature - a review. Separation and Purification Technology, 26, 195-205 (2002).

[14] van der Ven L., van Gemert M. L. M., Batenburg L. F., Keern J. J., Gielgens L. H., Koster T. P. M., Fischer H. R.: On the action of hydrotalcite-like clay materials as stabilizers in polyvinylchloride. Applied Clay Science, 17, 25-34 (2000).

[15] Delor-Jestin F., Lacoste J., Barros-Oudin N. Cardinet C., Lemaire J.: Photo-, thermal and natural ageing of ethylene-propylene-diene monomer (EPDM) rubber used in automotive applications. Influence of carbon black, crosslinking and stabilizing agents. Polymer Degradation and Stability, 67, 469-477 (2000).

[16] Harwood H. J.: Ethylene-propylene-diene monomer (EPDM) and fluorocarbon (FKM) elastomers in the geometrical environment. Journal of Testing and Evalution, 11, 289-298 (1983).
[17] Konar J., Samanta G., Avasthi B. N., Sen A. K.: Oxidative degradation of EPDM rubber using phase transferred permanganate as oxidant. Polymer Degradation and Stability, 43, 209-216 (1994).

[18] Kole S., Srivastava S. K., Tripathy D. K., Bhowmick A. K.: Accelerated hydrothermal weathering of silicone rubber, EPDM, and their blends. Journal of Applied Polymer Science, 54, 1329-1337 (1994).

[19] Wang X., Zhang H., Wang Z., Jiang B.: In situ epoxidation of ethylene propylene diene rubber by performic acid. Polymer, 38, 5407-5410 (1997).

[20] Bauer J., Behrens P., Speckbacher S., Langhals H.: Composite of perylene chromophores and layered double hydroxides: Direct synthesis, characterization and photo- and chemical stability. Advanced Functional Materials, 13, 241-248 (2003).

[21] Rana S., Tevtia A. K., Kumar B., Singh R. P., Tomer N. S.: Preparation and performance evaluation of EPDM nanocomposites under accelerated weathering. Journal of Thermoplastic Composite Materials, 19, 461-474 (2006).

[22] Tang L., Sallet D., Lemaire J.: Photochemistry of polyundecanamides. 2. $\mathrm{TiO}_{2-}$ and $\mathrm{ZnO}$-photocatalyzed oxidation. Macromolecules, 15, 1437-1441 (1982).

[23] Pandey J. K., Reddy K. R., Kumar A. P., Singh R. P.: An overview on the degradability of polymer nanocomposites. Polymer Degradation and Stability, 88, 234-250 (2005).

[24] Teissedre G., Pilichowski J. F., Chmela S., Lacoste J.: Ageing of EPDM-I: photo and thermal stability of EPDM hydroperoxides. Polymer Degradation and Stability, 53, 207-215 (1996).

[25] Duek E. R., Juliano V. F., Guzzo M., Kascheres C., De Paoli M-A.: The photo-oxidation of EPDM rubber: Part II, The photo-initiation process. Polymer Degradation and Stability, 28, 235-248 (1990).

[26] Duek E. R., De Paoli M. A.: The photo-oxidation of EPDM rubber: Part III, mechanistic aspects and stabilization. Polymer Degradation and Stability, 30, 283 292 (1990).

[27] Chang Y. Wang Y. Zha F.: Preparation and catalytic activity of polymer-supported 2,4-dihydroxybenzaldehyde-o-aminobenzoic acid complexes. Journal of Macromolecular Science, Part A: Pure and Applied Chemistry, 9, 889-896 (2003). 